\title{
REFLECTIONS
}

\section{To Care Is to Coprovide}

Stephen A. Buetow, PbD

Department of General Practice and Primary Health Care, University of Auckland, Auckland, NZ
Conflict of interest: none reported

\section{CORRESPONDING AUTHOR}

Stephen A. Buetow, PhD

Department of General Practice and Primary Health Care

University of Auckland

Private Bag 92019

Auckland, NZ 1004

s.buetow@auckland.ac.nz

\begin{abstract}
Although primary care, including family medicine, recognizes different types of clinician-patient interaction, I argue that only interactions characterized by coprovision define care. By coprovision I mean that clinicians and patients each provide the expertise in health care that they have the capacity to contribute in any given situation. I argue that paternalism and consumerism cannot signify care in any real sense. Some implications of this analysis include a reconceptualization of family medicine and its defining attributes; support for features of caring relationships, such as mutual responsiveness and responsibility; and an acknowledgment that clinicians and patients need to be self-regarding as well as other-regarding. In a previous issue of the Annals, I called for a new dictionary for family medicine, one that would redefine attributes of family medicine in ways not exclusively clinician-centric. Specifically, it would acknowledge the role of patients and their informal caregivers as coproviding, not merely consuming, health care.
\end{abstract}

Ann Fam Med 2005;3:553-555. DOI: 10.1370/afm.342.

To illustrate how family medicine defines itself through clinician-centric language, my previous contribution showed that continuity of medical care is not just "seeing the same professional."1 For young children, some older persons, and other dependent patients, continuity of care also requires consistency in who attends with, or for, the patient during successive visits. Attendance by different caregivers each time prevents consistency by fragmenting clinician interaction with the patient or those who care, speak for, or decide for the patient. I redefined clinician continuity to mean that the same patients and (any) informal caregivers visit the same clinician(s), service, or facility as an uninterrupted succession of events over time. Borkan ${ }^{2}$ notes that caregivers other than attending clinicians also contribute to continuity of medical care. My definition, however, focuses on continuity of care by those who coprovide care within and across successive visits and invites new definitions for other unique, visitbased attributes of family medicine: first-contact care, comprehensiveness, and coordination. ${ }^{3}$

I now wish to extend these arguments for a reconstituted family medicine by suggesting that, in most cases, to care is to coprovide. Primary care, including family medicine, currently recognizes different types of clinician-patient interactions, but I will argue that only the interactions involving coprovision define care in any real sense. In these terms, interactions not characterized by coprovision cannot be care or, indeed, family medicine/primary care.

The American Heritage Dictionary defines care as "attentive assistance to those in need." ${ }^{14}$ Literature from political ${ }^{5,6}$ and feminist theory ${ }^{7}$ and philosophy, ${ }^{8}$ for example, indicates that care is also an activity defining a connectedness with and respectful attention to the concrete needs of others and self. Care is part of a reciprocal relationship and intersubjective experience that the patient or clinician cannot define alone. Clinicians care with, rather than for, patients, and both benefit from care as a process and outcome. 
These definitions of care fit with a conceptualization of care as coprovision. By coprovision I mean that clinicians and patients each provide the expertise in health care that in any given situation they have the capacity to contribute. Clinicians contribute clinical expertise, whereas patients may be experts on their own bodies, life situations, values, beliefs, and preferences. ${ }^{9}$ My definition of coprovision allows for variation between and within these parties in their capacity to help deliver care

Coprovision shares many features of the models of mutual participation, ${ }^{10}$ accommodation, ${ }^{11}$ mutuality, ${ }_{1}^{12}$ and negotiated care. ${ }^{13}$ Notwithstanding exceptional circumstances, such as an emergency, coprovision assumes that clinicians and patients have sufficient power to clarify role ambiguities, negotiate differences of interest, and act on their own capacity. ${ }^{13}$ This power exists by virtue of each of these parties enabling the other to coprovide care. Without that power, their interaction is, at most, care in name only and emptied of the meaning of care as defined above. This analysis does not demand equality of capacity and power between patients and clinicians, because the resources and contributions of each party might not be easily compared, and equality is not always wanted or achievable.

Other types of clinician-patient interaction risk inappropriately locating control of the clinician-patient interaction in either the clinician or the patient. This fragmentation denies the freedom of the other party to coprovide care. The assumption, however, that these types of interaction involve care has gone unchallenged, including models of care that always give more control to the patient and less control to the clinician, for example, consumerism, ${ }^{14}$ or give more control to the clinician and less control to the patient, for example, paternalism. ${ }^{14}$

Paternalism typically prevents care. An exception perhaps is clinicians acting paternalistically to restore patient autonomy. ${ }^{15}$ For example clinicians might refuse to sign a work certificate to encourage a return to work of which the patient is capable. More often than not, however, paternalism disempowers patients. It weakens their ability to use their expertise to define their own explanatory model for interpreting and managing particular health care issues ${ }^{16}$ and discharge their roles and responsibilities as patients and persons. Paternalism thereby creates "the ethical problem of assuming responsibility for moral agents,"17 which can impose an unreasonable burden on clinicians and flies in the face of social movements, such as consumerism, socialism, and feminism. ${ }^{18}$

In turn, consumerism precludes care, as I have defined it, by devaluing and undermining clinicians' professional training, role, and personhood. Some patients cannot accept responsibilities, for example, to make health care decisions that are incompatible with low clinician control. In the informative or consumer model described by Emanuel and Emanuel, ${ }^{19}$ the clinician "cares for the patient in the sense of completely implementing the patient's selected interventions." This attribution of care reduces the clinician to a technician whose own values have no place and denies patients the opportunity to help define the menu of choices from which to select clinical interventions.

Theorists of the concept and practice of care have made the same mistake of viewing all clinical practice substantively as care. For example, Tronto ${ }^{5}$ has described how asymmetric relationships distort the practice of caring. From my perspective, however, this description misses the point that such relationships do not merely distort caring: they destroy its meaning. Any interaction to explore and meet patient needs that does not involve coprovision by competent adults cannot really be care.

This analysis has at least 5 key implications. First, it recognizes patients as coproviding, not merely consuming, health care. ${ }^{1,2}$ Second, family medicine/primary care must be redefined as first-contact, continuous, comprehensive, and coordinated care offered to and by patients, their informal caregivers, and clinicians. Types of clinician-patient interaction not involving coprovision (such as paternalism and consumerism) should no longer be regarded as care. Describing these interactions as care is misleading and gives them a credibility that in most cases is unjustified. Changing the definition of care is likely to discourage such interactions and indicates a need for policies to strengthen coprovision.

Third, care has distinctive features that define a framework for clinician-patient interactions in family medicine. These features include mutual responsiveness and responsibility. For example, clinicians and patients each have personal responsibilities, ${ }^{20}$ and informal caregivers who attend with, or for, patients must meet responsibilities that are waived when these patients lack competence. Some patients eschew their responsibilities for example, some older patients prefer to defer all control to the clinician. ${ }^{21}$ Regardless of what these patients prefer, however, both parties are obliged to coprovide medical care. ${ }^{22}$ Any failure of competent adults to participate in provision of care can make them liable for consequences of this behavior. For example, contributing to an adverse outcome by not sharing relevant information may make patients blameworthy and limit their ability to recover damages for a clinician's malpractice.

Fourth, although principally for patients' benefit, care fosters the ability of clinicians and patients to be self-regarding and other-regarding. As Barker observes, "the paradox of caring is that carers too gain a remarkable dividend." ${ }^{23}$ Clinicians and patients are each carers 
who benefit from receiving care as well as offering it as a reciprocal activity and mutual experience. The notion that clinician-patient interactions should involve care of, and not just by, clinicians is likely to appeal to the many clinicians who wonder what being a clinician and medical professional has come to mean. Caring empowers clinicians to "renegotiate their professional identity, including a reclamation of authentic meaning in medicine."14

Fifth, clinicians and patients should have to demonstrate their commitment to coprovision. Current moves to link clinicians' pay to measurable aspects of the quality of their care risk de-emphasizing areas, such as coprovision, not targeted for measurement. ${ }^{24,25}$ Surveys and observations of patient visits, however, may support assessment of coprovision, and educational programs may help to avoid and manage the underuse of coprovision by helping clinicians and patients to understand why this type of interaction underpins care. ${ }^{22}$

In conclusion, others have argued for clinicianpatient interactions that are based on some expression of partnership and that define patients as coproviding care. No one has previously suggested that types of interaction other than coprovision do not generally constitute care. Assuming a commitment to care, I have suggested that coprovision is the only type of clinicianpatient interaction that can help to define authentic family medicine in the 21 st century.

To read or post commentaries in response to this article, see it online at http://www.annfammed.org/cgi/content/full/3/6/553.

Key words: Delivery of health care; physician-patient relations; health services research; professional practice

Submitted December 5, 2004; submitted, revised, April 5, 2005; accepted April 21, 2005.

Funding support: This reflection was written during the tenure of a Senior Research Fellowship funded by ProCare Health Limited.

\section{References}

1. Buetow S. Towards a new understanding of provider continuity. Ann Fam Med. 2004;2:509-511.

2. Borkan J. Moving from clinician to patient-centric continuity [eletter]. http://www.annfammed.org/cgi/eletters/2/5/509\#1288, 17 November 2004.
3. Starfield B. Primary Care. Concept, Evaluation and Policy. New York, NY: Oxford University Press; 1992

4. American Heritage Dictionary of the English Language. 4th ed. Boston: Houghton Mifflin; 2000.

5. Tronto J. Moral Boundaries: A Political Argument for an Ethic of Care. New York, NY: Routledge; 1993.

6. Engster D. Care ethics and natural law theory. Toward an institutional political theory of caring. J Politics. 2004;116:113-135.

7. Gilligan C. In a Different Voice: Psychological Theory and Women's Development. Cambridge: Harvard University Press; 1982.

8. Brown J, Kitson A, McNight T. Challenges in Caring. Explorations in Nursing and Ethics. London: Chapman and Hall; 1992.

9. Tuckett D, Boulton M, Olson C, Williams A. Meetings between Experts: An Approach to Sharing Ideas in Medical Consultations. London: Tavistock; 1985

10. Szasz T, Hollander M. A contribution to the philosophy of medicine. Arch Int Med. 1956:97:585-592.

11. Siegler M. Searching for moral certainty in medicine: a proposal for a new model of the doctor-patient encounter. Bull New York Acad Med. 1981;57:56-69.

12. Roter DL, Hall JA. Doctors Talking with Patients. Patients Talking with Doctors. Westport, CT: Auburn House; 1992.

13. Buetow S. Four strategies for negotiated care. J Royal Soc Med 1998:91:199-201.

14. Buetow S. Beyond evidence-based medicine: bridge-building a medicine of meaning. J Eval Clin Pract. 2002;8:103-108.

15. Siegler M. The progression of medicine. Arch Int Med. 1985:145:713-715.

16. Kleinman A. Patients and Healers in the Context of Culture. Berkeley: University of California Press; 1980.

17. McMillan R. Responsibility to or for in the physician-patient relationship. J Med Ethics. 1995;21:112-115.

18. Goodyear-Smith F, Buetow S. Power issues in the doctor-patient relationship. Health Care Analysis. 2001;9:449-462.

19. Emanuel EJ, Emanuel L. Four models of the physician-patient relationship. JAMA. 1992;267:2221-2226.

20. Draper $H$, Sorell T. Patients' responsibilities in medical ethics. Bioethics. 2002;16:335-352

21. Coulter A. Partnership or partnership? BMJ. 1999;319:719-720.

22. Buetow S. High need patients receiving targeted entitlements: what responsibilities do they have in primary health care? J Med Ethics. 2005;31:304-306

23. Barker P. Reflections on caring as a virtue ethic within an evidencebased culture. Int J Nursing Studies. 2000;37:329-336.

24. Epstein AM, Lee T, Hamel M. Paying physicians for high-quality care N Eng J Med. 2004;350:406-410.

25. Roland M. Linking physicians' pay to the quality of care - a major experiment in the United Kingdom. N Eng J Med 2004;351:14481454. 